\title{
Primary writing tremor treated by stereotactic selective thalamotomy
}

\author{
C OHYE, M MIYAZAKI, T HIRAI, T SHIBAZAKI, H NAKAJIMA, Y NAGASEKI \\ From the Department of Neurosurgery, Gunma University School of Medicine, Maebashi, Gunma, Japan
}

SUMMARY Three cases with primary writing tremor were treated successfully by stereotactic selective thalamotomy centred mainly on the ventralis intermedius nucleus. They exhibited progressive coarse tremor of 5-7 $\mathrm{Hz}$ during writing, and Westphal's phenomenon on stretch, as the only neurological manifestations. Within the thalamus, a very high incidence of irregular burst discharges was recorded. These findings suggest that the writing tremor is an organic disorder.

Disordered writing with coarse tremor is frequently observed in patients with Parkinsonism, in those with postural tremor of various causes, and especially in those with action tremor due to cerebellar damage. Writing is used to demonstrate or exaggerate the tremulous movement in these cases. However, there is another type of writing disorder with coarse tremor which has been called primary writing tremor. ${ }^{1-3}$ This type of writing disorder is distinct from the previous ones in that it is manifested only when the patient intends to write. In pure form, the only problem is with writing, and other daily activities of life are undertaken normally. We present three cases with primary writing tremor, in which stereotactic thalamotomy resulted in complete relief.

\section{Case reports}

Case 1. In 1973 (four years before the first operation), a 47-year-old male clerk noticed that his right hand tended to tremble when he wrote. At that time it was controlled voluntarily by stiffening his right arm at writing, so he remained at work. This writing tremor was less after drinking a little alcohol (sake). However, the severity of his writing tremor gradually progressed, especially after midJuly 1976 when it increased so rapidly that he could scarcely write. He consulted a neurologist and was diagnosed as having writer's cramp. There was no history of any similar disorder in his family. Several medications were tried without noticeable change, and he tried many other therapies, including acupuncture, psychotherapy, moxa treatment, without benefit. Finally he was sent to our

Address for reprint requests: Dr Chihiro Ohye, Department of Neurosurgery, Gunma University School of Medicine, 3-39 Showa-machi, Maebashi, Gunma, Japan.

Received 6 February 1982 and in revised form 18 May 1982. Accepted 6 June 1982 neurosurgical clinic and was admitted on 1 March 1977 with a view to stereotactic treatment. Examinations then showed him to be very nervous and lacking in self confidence. His writing was severely distorted by coarse tremulous movement (fig 1A). However, other intended movements were quite normal. Finger to nose testing and point testing were performed without tremor. He could drink a cupful of water without difficulty. No resting or postural tremor was present. There were no cerebellar signs such as hypotonia, ataxia or dystonia. No other neurological abnormalities were found. Deep reflexes were normal and equal bilaterally. No abnormal reflexes were elicited. Laboratory data were normal. On EMG examination by surface electrodes, there was no abnormal discharge at rest or on raising the arm. During tasks such as finger to nose testing or finger to finger trial, transient grouped discharges at around $5 \mathrm{~Hz}$ were observed at the start and end of the movement. Both sides were affected but the right was slightly coarse. A most striking finding was a regular rhythmic grouping of about $6 \mathrm{~Hz}$ during writing movement, mainly in the forearm extensor muscles (fig $2 \mathrm{~A}$ ). The right side was far more markedly affected than the left, which also showed a slighter tendency of grouping. Passive stretch of the muscles revealed exaggerated tonic stretch reflex in biceps and an unequivocal Westphal's shortening reaction, especially in the biceps muscle (when the triceps muscle was stretched). During isometric voluntary contraction, slight tendency of grouped discharge was observed.

On 10 March, a left Vim (ventralis intermedius) thalamotomy was performed under local anaesthesia. Using Leksell's stereotactic apparatus, two semimicroelectrodes were introduced to record subcortical extracellular activities toward the tentative target point as described previously. ${ }^{4-7}$ The caudate nucleus, and then the upper border of the thalamus were identified by their characteristic neural activities. One of the most interesting findings was that many irregular burst discharges were encountered throughout the thalamic penetration. Several examples are shown in fig 3 . Interspike interval histogram showed a second peak corresponding to interburst interval (fig 4). It 
Primary writing tremor treated by stereotactic selective thalamotomy

(a)

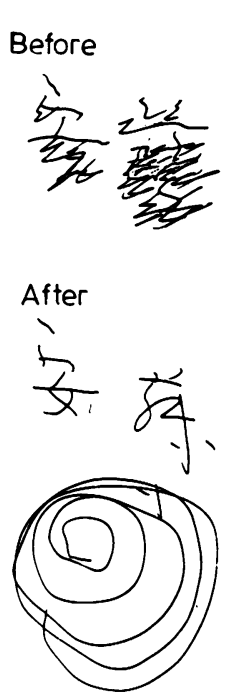

(b) Before

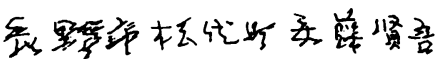

After

附曷站

中社作客

中不罂各

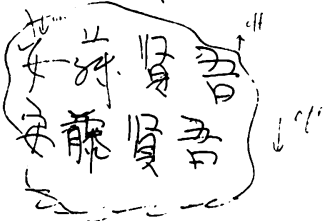

(c) Betore
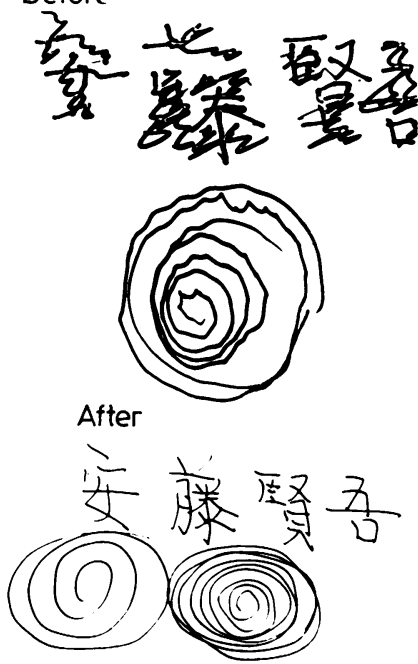

(d) (after 2.5)

31081

\section{安曾䝨營}

Fig 1 Examples of writing (name and/or spiral) in case 1, before and after the first (a), second (b) and third (c) operation respectively, and finally 2.5 years after the third operation (d).

(a) Before

KA 47 Male

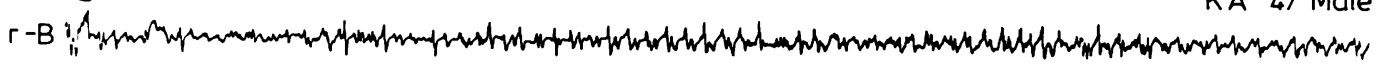
T

$\mathrm{F}$

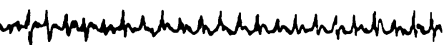

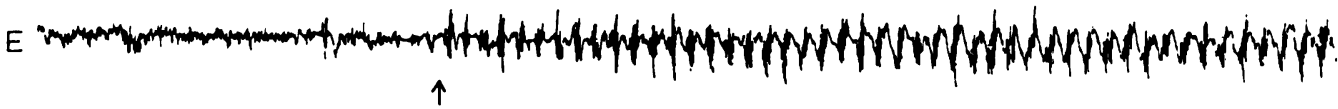
b After It thalamotomy

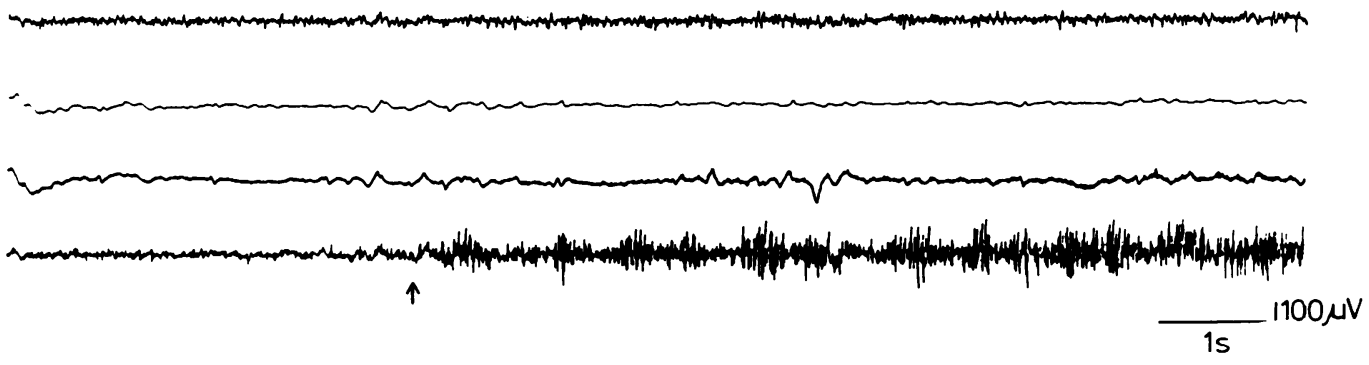

Fig 2 EMG recordings during writing in case 1, before (a) and after (b) the first operation. An arrow indicates approximate start of writing. $r$ : right, B: biceps brachii, $T$ : triceps brachii, $F$ : forearm flexors, $E$ : forearm extensors. 


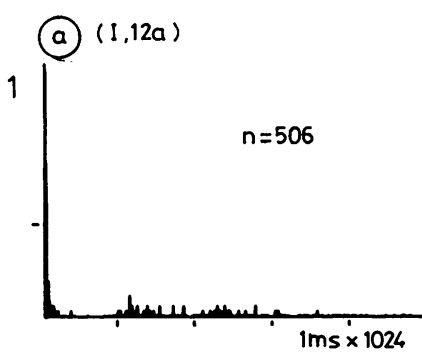

2

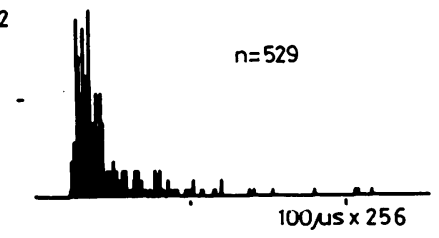

$20 \mu \mathrm{s} \times 1024$
A

KA 47 Male

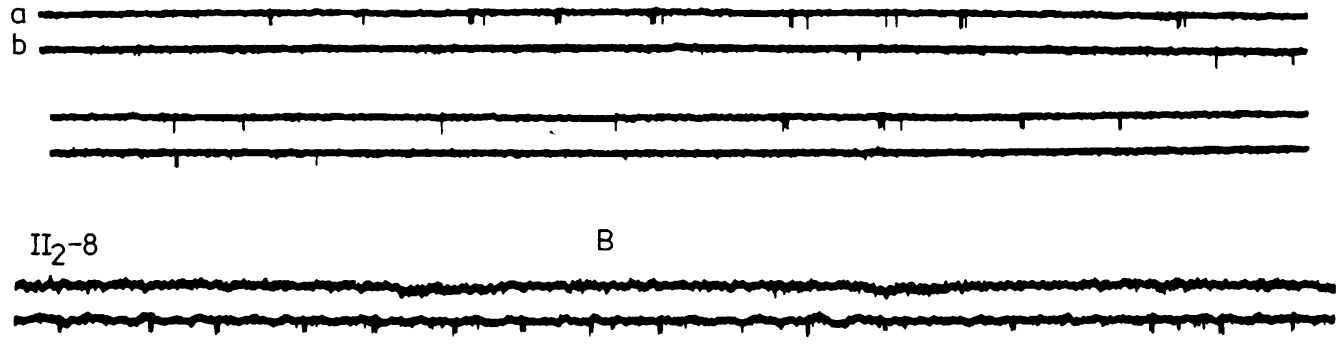

50, V

$200 \mathrm{msec}$

Fig 3 Examples of thalamic burst discharge recorded during the course of sterentactic operation in case 1 . (A) from the first operation (I), two sets of traces are continuous recording. (B) from the second trajectory of the second operation $\left(\mathrm{II}_{2}\right)$. Numbers (12 and 8) indicate distance in $\mathrm{mm}$ from the target. Each pair of traces $(a$ and $b)$ is simultaneous recordings from a pair of electrodes ( $c f$. fig 5 ).
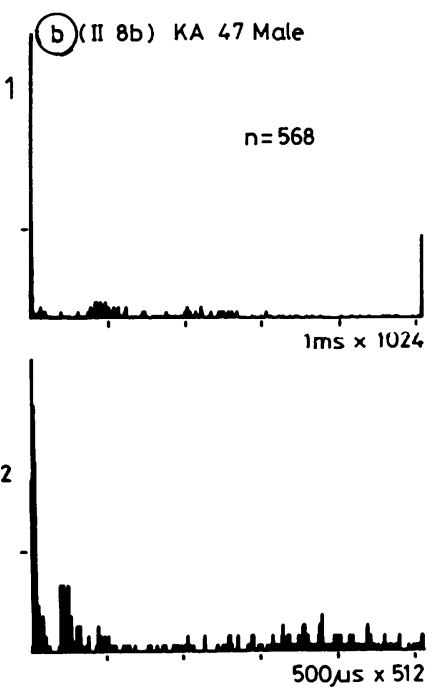

Fig 4 Interspike interval histogram of the thalamic burst discharges shown in fig 3, reproduced by FM magnetic tape and treated by a data recorder (ATAC 250 ,

Nihon-Kohden) (a) from the first operation (I) along a-track, $12 \mathrm{~mm}$ from the target, (b) from the second operation (II) along b-track, $8 \mathrm{~mm}$ from the target. Histograms are made by two different time base (1 and 2). On the bottom (3) is shown superimposed image of representative burst discharge triggered by the first spike of one burst with some delay (drawn by $X-Y$ plotter).

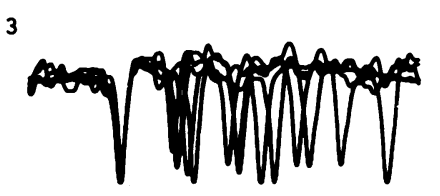

3

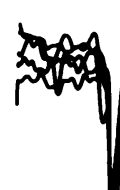



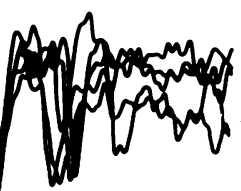

$20 \mu \mathrm{s} \times 1024$ 


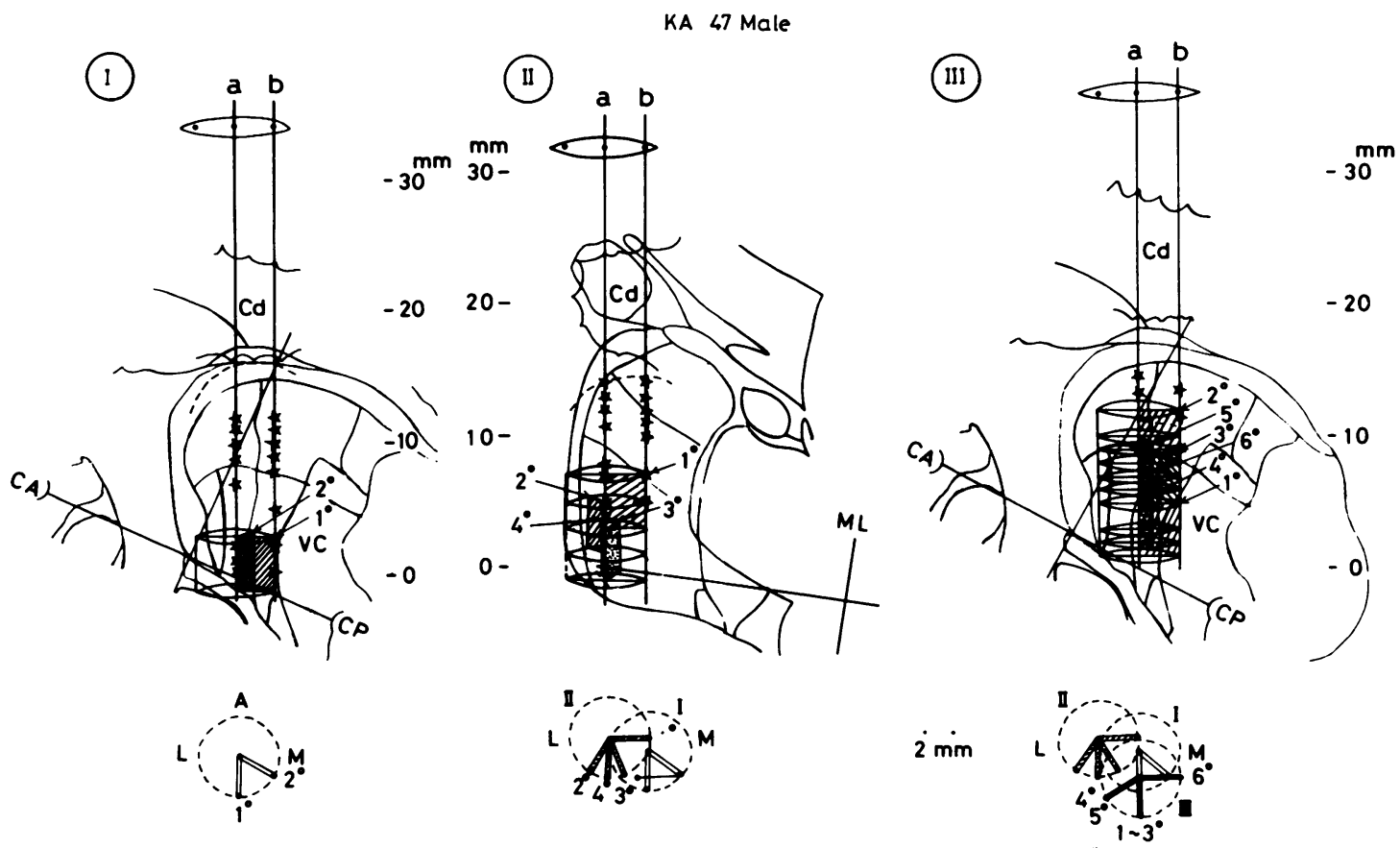

Fig 5 Operation data in case 1 obtained by three (I-III) successive operations. I and III: lateral view referring to the intercommissural line. II: frontal view referring to the intercommissural line and midline $(M L)$. In each figure, two vertical straight lines ( $a$ and $b$ ) indicate simultaneous recording tracks. For convenience, corresponding standard atlas of the human thalamus ${ }^{17}$ is superimposed in simplified form, respectively. For lateral view, the section at $15 \mathrm{~mm}$ from the $M L$ and for frontal view, about $7 \mathrm{~mm}$ from the posterior commissure are selected. Stars denote the site where burst discharges were recorded. Wavy short lines dissecting electrode tracks indicate border of the caudate (Cd) nucleus in each occasion. Dotted curve is the upper border of the thalamus. Extent of the lesion is shown by hatched or shaded area around immaginary cylinder of $3 \mathrm{~mm}$ radius, the overview of which is shown on the bottom, respectively, with the previous lesions if any. Length scale $(0$ to $30 \mathrm{~mm})$ is always referred to the a-track $(0=$ target point).

was generally not sharp indicating that the burst discharges were irregular. ${ }^{89}$ One burst consisted of 3-4 spikes. At least a total of 17 such burst discharges was recorded as shown in fig 5-I. They were distributed along two trajectories, being found more in the dorsal part of the thalamus. These burst discharges were independent of peripheral natural stimuli such as passive or active movement of the contralateral body, and the writing behaviour itself. Electrical stimulation $(60 \mathrm{~Hz}, 0 \cdot 2 \mathrm{~mA})$ of points $-2,-1,0,+1$ $\mathrm{mm}$ by the posterior electrode produced electric sensation around the contralateral palm (strongest .at 0 ), stimulation at +2 induced the electric sensation around the right angle of the mouth; sensation via the anterior electrode at the points $-2,-1,0 \mathrm{~mm}$ induced slight electric sensation in the contralateral fingers. In these tracks, no definite sensory units were identified, but at $-0.5 \mathrm{~mm}$ in the posterior track, a slight increase of the background noise was noticed on passive pronation of the right forearm. Taking account of these electrophysiological findings, the first coagulation was made at $+1 \mathrm{~mm}$ as the centre (effective length of coagulation electrode: $4 \mathrm{~mm}$, distance: $3 \mathrm{~mm}$ ), and the second coagulation was made at the same height but with posterior electrode turned about $60^{\circ}$ anteromedially (fig 5-I). The insertion of the coagulation electrodes caused the writing tremor to lessen, and after making lesion, it was abolished completely. There were no motor and sensory disturbances.

For two to three days after the operation the patient exhibited no tremor in writing (fig 1A), although he complained of some anxiety about writing. On the fifth postoperative day he noticed a slight tremulous movement during writing. A repeat EMG examination was made, but no abnormal discharges were found at rest or during several physical tasks. There was no weakness or hypotonia. Rigidity in the biceps was no longer detected, but during writing transient irregular grouped discharges (continuing for several seconds) were observed. This was so slight that his written letters were not disturbed. Abnormal grouped discharges during writing were estimated to occur about $10-20 \%$ of that seen in the preoperative state.

The tendency for anxiety during writing gradually got 
worse and, about 10 days after operation, occasional trembling of the letters was noticed (fig 1B). Accordingly, a second operation was performed on 23 March using the same burr hole, a pair of recording electrodes was inserted parallel to the coronal plane, this time $2 \mathrm{~mm}$ posterior to the previous target. Thalamic activity generally was low, but small irregular burst discharges were encountered in the dorsal thalamus. In the ventral thalamus, however, there was no electrical activity from +4.5 to -1 from the lateral electrode, and from +3 to -1 from the medial electrode, indicating that this area had been coagulated previously. The second track was made $2 \mathrm{~mm}$ lateral and $3 \mathrm{~mm}$ anterior to the first, and neural activity of the caudate nucleus and the thalamus was found as usual. However, there were many irregular burst discharges, again more in the dorsal thalamic area (fig 5-II); on this occasion at least 15 burst discharges were identified. Electrical stimulation at this site did not produce any sensory or motor effect, except for some electrical sensation around the contralateral wrist and hand on stimulating below o point (probably, below the thalamus). Considering this anatomical relation to the previous lesions, four lesions were added as shown in fig 5-II. Immediately after the coagulation, his writing had improved and no tremor was evident. However, he showed transient confusion in that he wrote his former surname instead of his actual surname (he had changed his surname after marriage) (fig 1B); this occured only on three successive occasions, and then returned to normal. There were no other intellectual, motor or sensory disturbances. His writing was normal without tremor or EMG grouping (fig 2B) when he was discharged 15 days after the second operation.

The writing tremor did not re-appear for another three months, but around July 1977 he noticed some difficulty, and from about April 1978 the writing tremor reappeared and gradually increased. Therefore, a third operation was planned and he was admitted again on 11 November 1978. There were no special neurological findings except for slight hypotonia of the right upper limb and inconstant writing tremor. EMG examination revealed transient grouped discharges at $6 \mathrm{~Hz}$ in the right forearm muscles only during writing, although sometimes he could write without tremor. For example, while writing a continuous long spiral, grouped discharges appeared suddenly for 1-2 s, disappeared thereafter for a while, then reappeared again (fig 1C). A maximal voluntary contraction caused grouped discharge at about $10 \mathrm{~Hz}$. There was no exaggeration of the tonic stretch reflex, and there was no weakness. On 13 November 1978, the third thalamotomy was performed. The previous burr hole was extended anteriorly and a pair of recording electrodes was introduced $2 \mathrm{~mm}$ posterior to the first target point, parallel to the parasagittal plane. The extent of the caudate nucleus and the entrance point of the thalamus was identified (fig 5-III). Within the thalamus many irregular burst discharges were encountered again, especially in the dorsal thalamus as shown in fig 5-III. This time a total of six burst discharges were identified. In the anterior track, the neural activity decreased suddenly from $6.0 \mathrm{~mm}$, indicating the zone coagulated by the previous operation. The neural activity along the posterior track also decreased from $4.5 \mathrm{~mm}$. Electrical stimulation of the ventral thalamus along the anterior track had no effect, but stimulation at the posterior thalamic points induced electrical sensations in the contralateral palm and I-II fingers ( 0 to $+4 \mathrm{~mm})$, and exaggeration of EMG grouped discharges in deltoid muscle. In order to make a large coagulative lesion, six planes extending from +12 to +1 dorsoventrally were coagulated as shown in fig 5-III. During the procedure of coagulation, tests of writing (name, spiral, etc) were continued to demonstrate changes in tremor which was abolished completely. There were no motor, sensory or mental complications. Writing was repeatedly examined postoperatively and it always was perfect (fig 1C). Since the third operation, tremor never appeared during writing, even after the great psychological shock of the sudden death of his wife at the end of 1980 . His writing 2.5 years after the third operation is shown in fig $1 \mathrm{D}$.

Case 2. A 36-year-old male teacher at a high school had been aware of writing tremor since childhood when in the 5-6th grade of primary school. There was no history of any similar disorder in his family. At the age of about 20 years, he sought medical aid and was treated with several drugs without effect; finally he was sent to our clinic on 13 March 1978. On admission, his physical and mental conditions were normal. A CT scan showed no abnormal findings and other investigations were normal. Neurological examination revealed slight intention tremor of both arms, most obvious in the distal part of the right arm. Repeated pronation-supination movements were not executed smoothly, especially on the right, but there was no definite cerebellar signs such as hypotonia, dysmetria, decomposition or ataxia. EMG examination by surface electrodes revealed no abnormal discharges at rest or on maintaining a posture (for example, on raising the arms), but there were transient reciprocal grouped discharges at 7-8 $\mathrm{Hz}$ during movement. During writing, somewhat irregular grouped discharges at about $5 \mathrm{~Hz}$ continued predominantly in biceps and forearm extensor muscles (fig 6). There was no exaggeration of the stretch reflex, but Westphal's phenomenon was observed in forearm extensor muscles when the antagonist was stretched passively. During maximum isometric contraction, rapid grouped discharges at 9-10 $\mathrm{Hz}$ continued. On 20 March 1978, a left stereotactic thalamotomy was performed. With a pair of semimicroelectrodes, the first track was made parallel to the parasagittal plane and the extent of the caudate nucleus and the point of entering into the thalamus were identified by the background activity (fig 7A). Within the thalamus, many irregular burst discharges were found; at least 14 burst discharges were identified, located mainly in the dorsal part of the thalamus (fig 7A). No sensory neurons were encountered. Electrical stimulation $(60 \mathrm{~Hz}, 0.2 \mathrm{~mA})$ of the points $-2+3 \mathrm{~mm}$ along the posterior track induced paresthesiae in the mouth or pharyngeal region, so the track was thought to be too medial. A second track was then made by turning the posterior electrode $90^{\circ}$ laterally, the anterior electrode remaining as it was. This time, the electrode was advanced quickly and only burst discharges due to injury were observed. At $+2 \mathrm{~mm}$, passive elbow flexion induced a slight increase of background noise but no definite spike response. Along this track, electrical stimulation of the points +2 and $+3 \mathrm{~mm}$ produced 


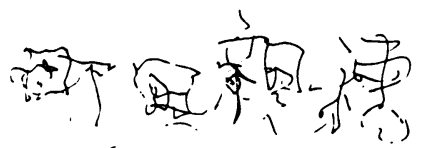



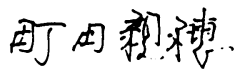

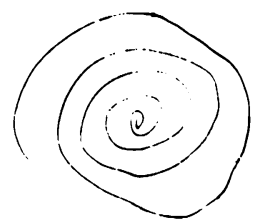

After thalamotomy

Fig 6 Examples of writing (name and spiral) and EMG recordings during writing in case 2, before (a) and after (b) thalamotomy. R: right, D: deltoid, B: biceps brachii, T: triceps brachii, F: forearm flexors, E: forearm extensors.

CM 36 Male

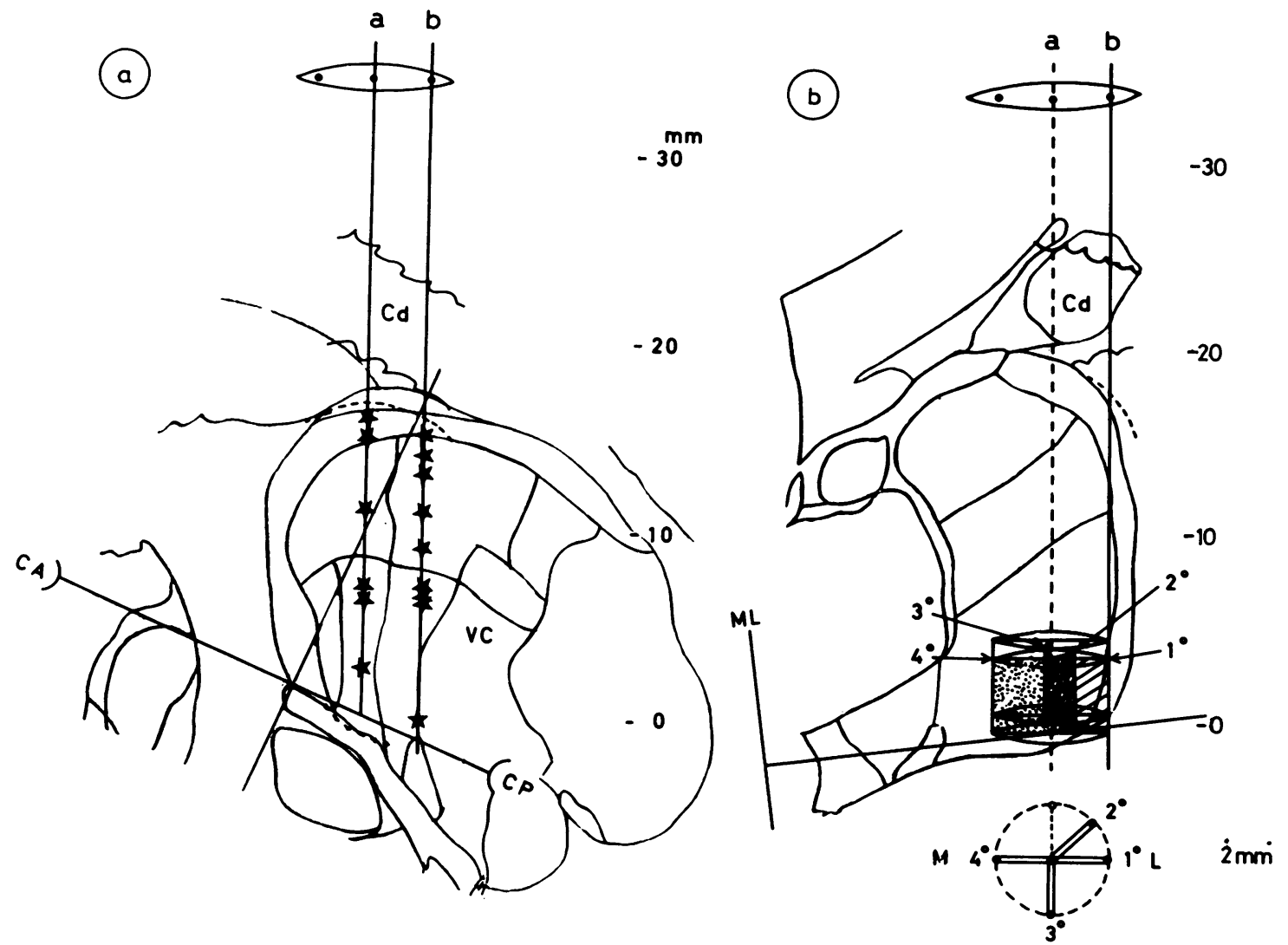

Fig 7 Operation data in case 2, obtained by the first (a, lateral projection) and the second trial (b, frontal projection). The figure is drawn in the same manner as in fig 5 . In (b) a-track (dotted line) was the same as in a. Four conagulation lesions were made after the second trial. 
paresthesiae in the right upper and lower limbs. Finally, coagulative lesions were placed at four planes, not touching that of the first track (fig 7B). After the first coagulation, the writing disorder improved greatly, and after fourth lesion, it completely disappeared (fig 6B). There was no motor, sensory or mental change. Since then, he has been quite satisfactory at writing and remained at work as a high school teacher.

Case 3. A 49-year-old male clerk of a village office had tremor on movement for 10 years, especially during writing. He noticed that the writing tremor subsided after drinking alcohol, but several drugs were administered without effect. There was no history of any similar disorder in his family. He was admitted to our clinic on 5 March 1979. Neurological examination revealed no abnormal findings except for tremor on movement of both limbs and writing, the right side being more affected. For example, during finger to nose testing, tremor at $6-7 \mathrm{~Hz}$ at the distal point, and $8-10 \mathrm{~Hz}$ at the proximal position, was observed. Writing was greatly disturbed (fig $8 \mathrm{~A}$ ), but the severity of the writing disorder fluctuated. Sometimes he could write relatively smooth letters, but at other times, tremor was (a) Betore thalamotomy



(b) After thalamotomy

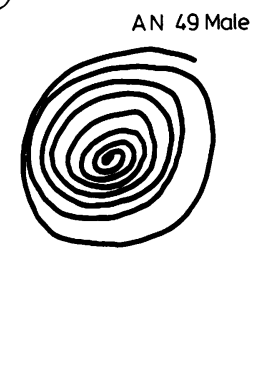

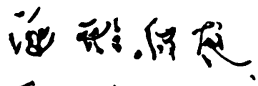

借

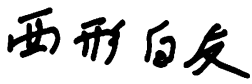

Fig 8 Examples of writing (name and spiral) before (a) and after (b) thalimotomy in case 3.

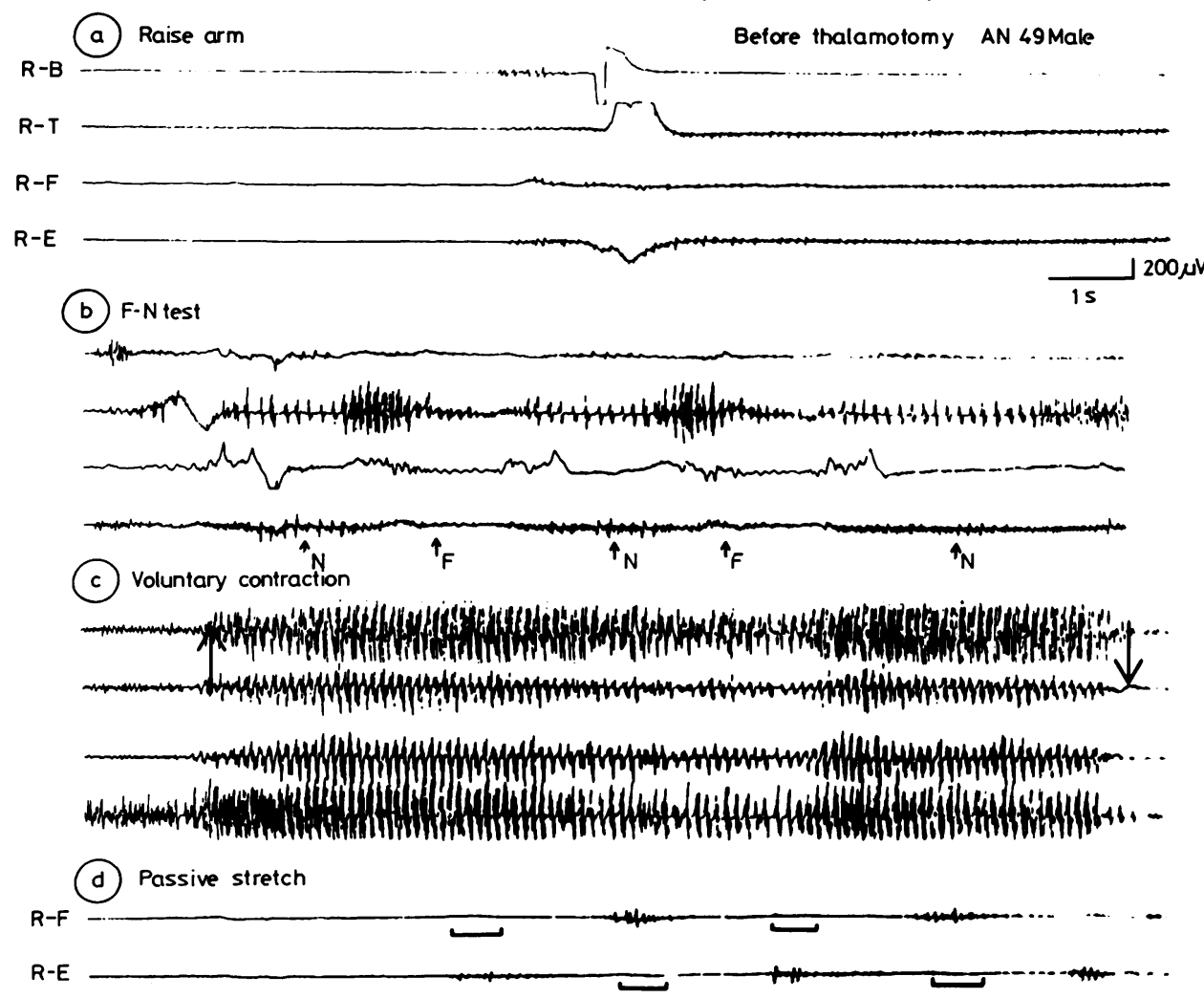

Fig 9 EMG recordings during several active and passive manoeuvres before thalamotomy in case 3. (a) raising arm, (b) finger to nose testing. Small arrows indicate approximate time when patient's finger touched to his nose $(N)$ or to examiner's finger $(F)$. (c) voluntary isometric contraction of biceps brachii on command. An upward arrow denotes on-sign and a downward arrow off-sign. (d) Repeated stretch of the forearm flexors $(F)$ and extensors $(E)$. Short bars denote approximate time of stretch. 
exaggerated. On EMG examination, there were no abnormal discharges at rest in supine position, and the simple task of raising the arm did not cause grouped discharges (fig 9A). During finger to nose testing, grouped discharges were observed especially in the right triceps muscle (fig 9B). During writing with the right hand, somewhat irregular grouped discharges at $5-7 \mathrm{~Hz}$ was marked in the triceps and forearm extensor muscles. Writing with the left hand was accompanied by transient grouped discharges of small amplitude at around $10 \mathrm{~Hz}$ in deltoid and forearm muscles. Stretch reflexes were not exaggerated, but Westphal's phenomenon was observed in forearm flexor muscle when the extensors were passively stretched (fig 9D). During isometric voluntary effort, grouped discharges at $9-10 \mathrm{~Hz}$ continued (fig 9C). No cerebellar signs such as hypotonia, dysmetria, or ataxia were detected. A CT scan was normal. Stereotactic left thalamotomy was performed on 12 March 1979. A pair of recording electrodes was introduced parallel to the parasaggital plane to the tentative target point as shown in fig 10. On the basis of their characteristic background activity, the caudate nucleus and the point of entrance into the thalamus were delineated. Within the thalamus, irregular burst discharges were encountered; at least nine such burst discharges were identified. No definite sensory response was elicited. Electrical stimulation induced several sensory and motor responses. At +1 and $+2 \mathrm{~mm}$ along anterior track (fig 10 , a-track), stimulation exaggerated the tremor during writing (fig 11). At -2 to $0 \mathrm{~mm}$, along the posterior track (fig 10,b-track) stimulation induced an electrical sensation or paresthesiae around the mouth or throat, and at $+1 \mathrm{~mm}$ a similar sensation was provoked in the right hand. Since the posterior track was related more to the mouth area, two coagulations were made in the plane $45^{\circ}($ centre +2$)$

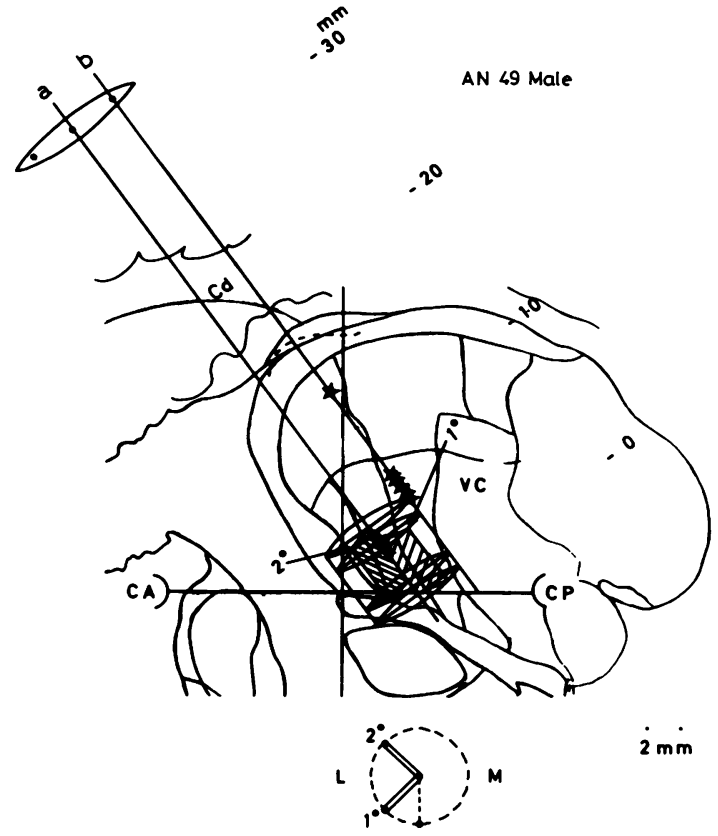

Fig 10 Operation data obtained in case 3. Lateral projection. The figure is drawn in the same manner as in fig 5.

AN 49 Male

Fig 11 Effect of thalamic stimulation at $1 \mathrm{~mm}$ above the target along a-track shown in fig 10, during writing in case 3. EMG was recorded simultaneously with a spiral drawing shown above. Note exaggerated zig-zag and EMG grouped discharge during stimulation, indicated by a thick bar in the bottom trace. Abbreviations on EMG traces are the same as in fig 6 .
$R-E$

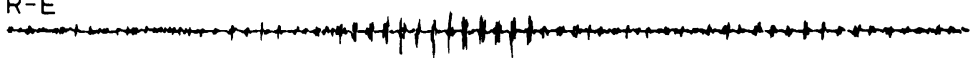



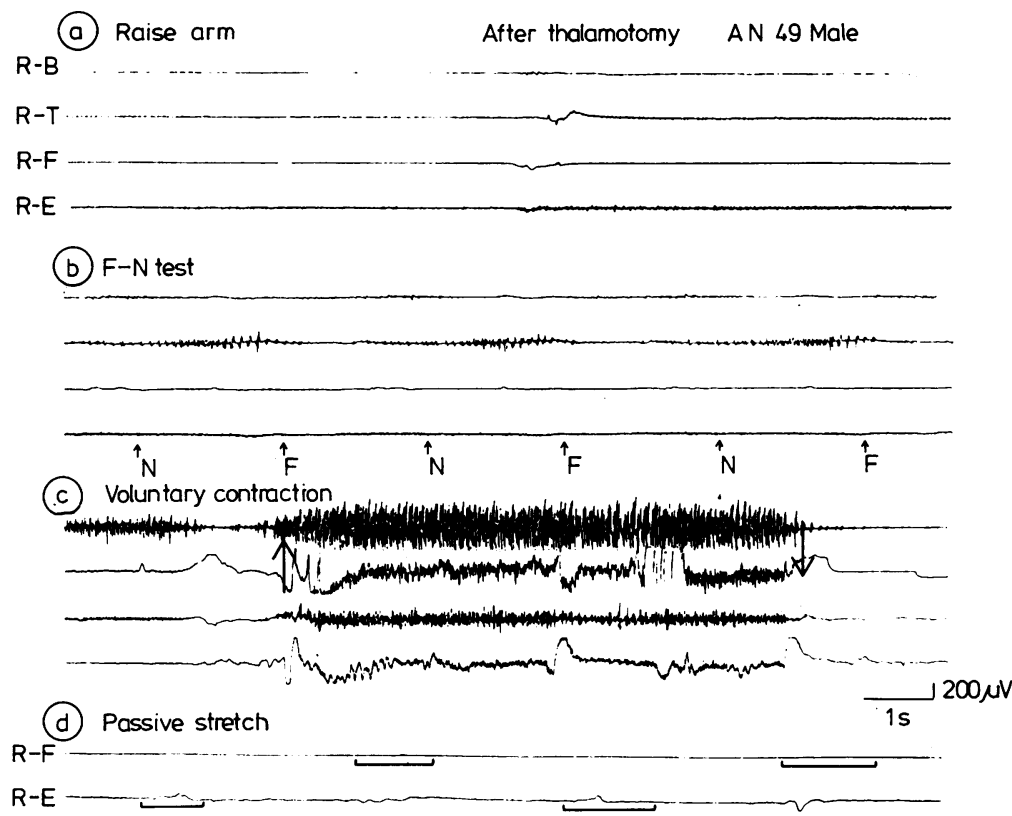

Fig 12 EMG recordings during the same manoeuvors as shown in fig 9 in case 3, but after thalamotomy. Abbreviations are the same as in figs 6 and 9. and $135^{\circ}$ (centre +3$)$ anterolateral to the recording track (fig 10). Immediately after the first coagulation the writing tremor disappeared and letters and lines becoming smooth and straight. There were no motor, sensory or mental deficits. After the operation, his writing tremor was absent (fig 8B), although EMG examination on the 8th day after operation revealed a slight tendency to grouped discharge of low amplitude around $9-10 \mathrm{~Hz}$ in biceps and triceps during finger to nose testing, and during isometric voluntary contraction (fig 12A-C). Westphal's phenomenon also was abolished in the right arm (fig 12D). He was discharged on 22 March 1979, with no problems in writing since then.

\section{Discussion}

The common neurological findings in these patients were a disorder of writing tremor, and Westphal's phenomenon which has been considered to be one of the extrapyramidal manifestations ${ }^{10}{ }^{11}$ revealed by EMG examination, bilaterally. There was no postural tremor, and no cerebellar signs. Amongst these three cases, the first was the pure form of writing tremor, no other abnormality being detected. In the other two cases, although the main objective complaint was writing tremor, there was some tendency to tremor on other movements.

Although there was no family history in these cases, they did show some resemblance to "essential tremor"..$^{12}$ Our cases may represent a rare form of essential tremor, which may be called primary writing tremor. Rothwell et $a l^{2}$ described a special case of primary writing tremor in which abrupt jerky movement occurred on writing. In their case, the jerky movement consisted of a burst of rhythmic oscillation, which they described as a focal tremor. Our cases differ from theirs in that reciprocal rhythmic grouped discharges continued during writing without any jerky movement. They also concluded that their case represented an isolated variant of essential tremor.

The pathology of essential tremor is not known, ${ }^{14}$ and its treatment is difficult. Stereotactic thalamotomy was considered in the present cases because of its efficacy in other types of tremor such as Parkinson's disease, as after trauma or stroke, and in typical essential tremor. ${ }^{15}$ During the course of the operation, many burst discharges were encountered within the thalamus in all cases. This is of particular interest because the incidence of burst discharges in these cases was much higher than that in Parkinson's disease; it was comparable to that in the anaesthetised thalamus. ${ }^{8}$ In other words, the thalamic nuerons in cases with writing tremor behaved as if they were deafferented or sleeping. Although these burst discharges seemed to be independent of the tremor, as they were not influenced by natural peripheral stimuli, nor were they timelocked to the peripheral tremor, they might play some role in the genesis of writing disorder. The most numerous irregular burst discharges were found in the first patient who was the most severely affected, and their burst discharges diminished in 
parallel with the amelioration of writing tremor in the course of the three consecutive operations. The site of tracks during the exploratory stereotactic operation was limited and the sampling was uneven, so other thalamic area also may be involved in burst discharges. These abnormal burst discharges may disturb smooth execution of the most complex voluntary movement of writing. Finally, selective Vim thalamotomy has been shown to be an effective treatment for this type of tremor, as well as for other types of tremor. This is in favour of our assumption that Vim nucleus is primarily concerned with the tremor maintaining mechanism regardless of the types of tremor. ${ }^{16}$

\section{References}

${ }^{1}$ Raverdy P. Essai sur la semiologie de la main en clinque neurologique. Thèse, Paris 1955;198-202.

${ }^{2}$ Rothwell JC, Traub MM, Marsden CD. Primary writing tremor. J Neurol Neurosurg Psychiatry 1979;42:1106-14.

${ }^{3}$ Klawans HL, Tanner CM, Goetz CG, Nausieda PA, Weiner WJ, Glantz R. Primary writing tremorSelective action tremor of the upper extremity. (Abstract) Neurology (Minneap) 1981;31(Part 2):80.

4 Ohye C, Fukamachi A, Miyazaki M, Isobe I, Nakajima H, Shibazaki T. Physiologically controlled selective thalamotomy for the treatment of abnormal movement by Leksell's open system. Acta Neurochir 1977;37:93-104.

${ }^{5}$ Fukamachi A, Ohye C, Saito Y, Narabayashi H. Estimation of the neural noise within the human thalamus. Acta Neurochir 1977;Suppl 24:121-36.
- Nakajima H, Fukamachi A, Isobe I, Miyazaki M, Shibazaki T, Ohye C. Estimation of neurol noiseFunctional anatomy of the human thalamus. Apl Neurophysiol 1978;41:193-201.

${ }^{7}$ Ohye C, Narabayashi H. Physiological study of presumed ventralis intermedius neurons in the human thalamus. J Neurosurg 1979;50:290-7.

${ }^{8}$ Ohye C, Saito Y, Fukamachi A, Narabayashi H. An analysis of spontaneous rhythmic and non-rhythmic burst discharges in the human thalamus. $J$ Neurol Sci 1974;22:245-59.

${ }^{9}$ Ohye C, Albe-Fessard. Rhythmic discharges related to tremor in humans and monkeys. In: Chalazonitis $\mathbf{N}$, Boisson M, eds. Abnormal Neuronal Discharges. New York: Raven Press, 1978:193-201.

${ }^{10}$ Rondot P, Metral S. Analysis of the shortening reaction in man. In: Desmedt JE, ed. New Developments in Electromyography and Clinical Neurophysiology. Vol 3. Basel: Karger, 1973:629-34.

$"$ Chida T, Yokochi M. Clinical and electromyographical analysis on Westphal phenomenon (Japanese). Clin Electroencephalogy 1978;20:533-40.

${ }^{12}$ Critchley M. Observations on essential (heredofamilial) tremor. Brain 1949;72:113-30.

${ }^{13}$ Critchley. E. Clinical manifestation of essential tremor. $J$ Neurol Neurosurg Psychiatry 1972;35:365-72.

${ }^{14}$ Herskovits E, Blackwood W. Essential (familial, hereditary) tremor: a case report. J Neurol Neurosurg Psychiatry 1969;32:509-11.

is Ohye C, Hirai T, Miyazaki M, Shibazaki T, Nakajima H. Vim thalamotomy for the treatment of various kinds of tremor. Appl Neurophysiol 1982;45:275-80.

${ }^{16}$ Ohye C. Neurol mechanism of tremor (Japanese). $A d v$ Neurol Sci 1981;25:106-17.

${ }^{17}$ Schaltenbrand G, Wahren W. Atlas for Sterotaxy of the Human Brain. 2nd ed. Stuttgart: G Thieme, 1977. 